\title{
A Ruptured Cornual Ectopic Pregnancy at 17 Weeks Gestation : A Case Report
}

\author{
KHAN MI ${ }^{\mathrm{a}}$, NYEER $\mathrm{R}^{\mathrm{b}}$, LAILA $\mathrm{R}^{\mathrm{c}}$, JAHAN $\mathrm{S}^{\mathrm{d}}$
}

\begin{abstract}
Cornual pregnancy is a specific variety of ectopic gestation which occurs in the rudimentary horn of the uterus. It often rupture later than other tubal pregnancies because the myometrium is more distensible than the fallopian tube.Traditionally, the treatment is cornual resection (removal of rudimentary horn) or hysterectomy
\end{abstract}

\section{Introduction:}

Cornual pregnancy is a rare form of ectopic pregnancy. Insterstitial pregnancies account for 2-4\% of ectopic pregnancies and $20 \%$ of cases that advances beyond 12 wks of gestation ends in rupture ${ }^{1}$. As pregnancy location is within the myometrium there is greater room for expansion and rupture occurs characteristically during the fourth or fifth gestation ${ }^{2}$. It is very difficult to make a diagnosis of cornual pregnancy before rupture. We report a case where cornual pregnancy was diagnosed at 17 weeks of gestation after uterus rupture and profuse intraabdominal heamorrhage.

\section{Case Report:}

A 22 yrs old lady admitted in our hospital with history of severe abdominal pain and sweating for 5 hours at 17 weeks of gestation. . Her temperature recorded $96^{\circ} \mathrm{F}$, pulse rate was 115 beats/min and blood pressure was 80/50 mm Hg. The lower abdomen

a. Dr. Masuda Islam Khan, FCPS (Gynae \& Obs), Registrar, Obs \& Gynae, Ibrahim Medical College \& BIRDEM Hospital

b. Dr. Riffat Nayeer, MBBS, Assistant Registrar, Obs \& Gynae, BIRDEM Hospital

c. Dr. Rona Laila, MS (Gynae \& Obs), Resident Surgeon, Obs \& Gynae, BIRDEM Hospital

d. Dr. Shamsad Jahan, MS (Gynae \& Obs), Associate Professor, Obs \& Gynae, Ibrahim Medical College \& BIRDEM Hospital

Address of Correspondence: Dr. Masuda Islam Khan, FCPS (Gynae \& Obs), Registrar, Department of Gynaecology and Obstetrics, Ibrahim Medical College and BIRDEM. Email: masudaislamkhan@yahoo.co

Received: November 11, 2012 Accepted: December 31, 2013 where the pedicle is short and the attachment is wide. Here, we report a case where cornual pregnancy was diagnosed at 17 weeks of gestation after uterine rupture and profound haemorrhage. The patient underwent laparotomy followed by cornual resection with salpingectomy.

(Birdem Med J 2013; 3(2): 50-51)

was slightly distented and tender. She was severely anaemic and dehydrated. She had gestetional diabetes mellitus at 11 weeks of pregnancy . She gave a history of spontaneous abortion at 10 weeks of pregnancy 2 years ago.Initial labratory tests included Haemoglobin was $7 \mathrm{gm} \%$; haematocrit was $22.6 \%$ and platelet count was within normal limit. On abdominal ultrasonography, uterus found normal in size, endometrial cavity was empty and a 17 weeks old dead fetus was in the abdominal cavity with massive free fluid. An emergency laparotomy was performed under general anaesthesia with transfusoin of 3 bags of fresh blood. There was approximately $3000 \mathrm{ml}$ of blood in the abdominal cavity with a $16 \mathrm{~cm}$ male fetus protruded from ruptured right cornual region of the uterus. Placenta adherent to right horn of uterus which was ruptured. Left fallopian tube and both ovaries were normal. Right horn of the uterus with right tube was dissected and bleeding was secured. Perioperatively she received in total 4 units of blood. A drain tube was kept in peritoneal cavity which was removed on $3^{\text {rd }}$ postoperative day. The postoperative period was unevenful and she was discharged on $6^{\text {th }}$ postoperative day.

\section{Discussion}

Cornual pregnancy is the least frequent variety of ectopic pregnancy and its occurance is rare. The etiologic factors for cornual pregnancy are pelvic inflammatory disease, tumour, a high number of transferred embryos, a transfer near the uterine horn, excessive pressure on the syringe during the transfer, or difficulties during the ET procedure ${ }^{3}$. Bilateral 
salpingectomy is likely to be another risk factor for cornual pregnancy ${ }^{4}$. Peri- and intratubular adhesions, related or not related to endometriosis, are an additional risk factor. Some authors also consider the quality of the embryos and the hormonal milieu at the moment of transfer as possible causes ${ }^{5}$.

In general, ectopic gestation is rarely diagnosed before rupture or haemorrage takes place. Cornual pregnancy is diagnosed wih ultrasonographical criteria in the presence of a positive hCG level indicating pregnancy ${ }^{6}$. These criteria are: no gestation sac in the uterine cavity; located gestational sac in close proximity to the uterus; observing a thin myometrial wall or thick muscle layer around the gestation sac.It has been also used transvaginal three-dimensional ultrasound scanning with its capacity to reproduce the coronal plane of the uterus ${ }^{7}$. So, it is clear that the diagnosis of cornual pregnancy is dependent on the quality of ultrasound and the skills of investigator especially in haemodynamically stable patients. MRI scan may be a useful tool to the diagnosis of cornual ectopic pregnancy in doubtful cases.

The treatment modalities range from medical treatment to more invasive surgical techniques. When an unruptured cornual pregnancy is diagnosed, there is some medical treatment options, such as medical management with applied by parental route or directly injection of methotrexate or potassium chloride into the cornual gestational sac with ultrasonography guidance, laparoscopic cornual resection and selective uterine artery embolization when uterine preservation is desired $7,8,9$. One of the major advantages of conservative treatment of cornual pregnancy is the preservation of fertility and the key disadvantages is the risk of uterine rupture in subsequent pregnancy ${ }^{10}$.

Traditionally after rupture, treatment is laparotomy with hysterectomy or cornual resection. The scar left by cornual resection may play an important role in future childbearing. The larger resection, more the scar is comparable to that of a classical Cesarean section or extensive myomectomy. So, that patients who have had extensive cornual resection should be delivered preferably by elective Cesarean section ${ }^{11}$.

U. Ince et al. report a case where cornual pregnancy was diagnosed by ultrasonography at $18 \mathrm{wks}$ of gestation after uterine cornual rupture and profound haemorrhage. During laparatomy, the cornua was found to be largely ruptured with massive haemorrhage in the abdominal cavity. Therefore no other coservative methods seemed to be possible, then the patient underwent hysterectomy ${ }^{12}$.

In our case, because of the advanced condition of the pregnancy, the uterine cornu(Right) was found to be ruptured with massive haemorrhage in the abdominal cavity. So, cornual resection wih right sapingectomy was done.

Early diagnosis of ectopic pregnancy is the cornerstone in reducing the morbidity and mortality from ectopic pregnancy.

\section{References}

1. lan S, Tulandi T. Conservative medical and surgical management of interstitial ectopic pregnancy. Fertile Steril.1999; 72: 207-15.:

2. Jung W. Lee, S. O. Chung: Unruptured Cornual Pregnancy: A Case Report. Yonsei Med. Journal. Vol. 16, No. 1, 1975.

3. Chang Y, Lee JN, Yang CH, Hsu SC, Tsai EM: An unexpected quadruplet heterotopic pregnancy after bilateral salpingectomy and replacement of three embryos,Fertil Steril 2003;80:218-20.

4. Agarwal SK, Wisot AL, Garzo G, Meldrum DR : Cornual pregnancies in patients with prior salpingectomy undergoing in vitro fertilization and embryo transfer, fertile stertil 1996;65:659-60.

5. Pan HS, Chuang J, Chiu SF, Hsieh BC, Lin YH, Tsai YL, et al. Heterotopic triplet pregnancy:report of a case with bilateral tubal pregnancy and an intrauterine pregnancy. Hum Reprod 2002;17:1363-66.

6. Graham M, Cooperberg PL: Ultrasound diagnosis of interstitial pregnancy:findings and pitfalls. J Clin Ultrasound 1979;7:433-37.

7. Valsky DV, Hamani Y, Verstandig A, Yagel S: The use of 3D rendering, VCI-C, 3D power Doppler and Bflow in the evaluation of interstitial pregnancy with arteriovenous malformation treated by selective uterine artery embolization. Ultrasound Obstet Gyncol 2007; 29: 352-55.

8. Tulandi T, Vilos G, Gomel V: Laparoscopic treatment of interstitial pregnancy. Obstet Gynecol 1995; 83: 465-67.

9. Woodland MB, Depasquale SE, Molinari JA, Sagullo C: Laparoscopic approach to interstitial pregnancy. J Am Assoc. Gynecol Laparosc 1995;3: 439-41

10. Moon HS , Choi YJ, Park YH, Kim SG: New simple endoscopic operations for interstitial pregnancies. Am J Obstet Gynecol 2000; 182: 114-21.

11. Felmus, L.B. Pedowitz, P: Interstitial pregnancy. Am. J. Obst. And Gynae. 1958;66:127. 66:

12. U. Ince, M.A. Osmanagaoglu, H. Bozkaya AGynaecology ruptured cornual ectopic pregnancy at 18wks gestation: A case report. The Journal of and Obstetrics. 2008 Vol. 9; I-2:p-5. 